\title{
Concept of Logistics Management: A Holistic Approach to Business Performance Management
}

\author{
Prof. Zdravko Zekić Ph.D. \\ Faculty of Economics and Business \\ University of Rijeka \\ Croatia
}

\begin{abstract}
Rapid and extensive changes in all business environment segments, especially those changes that have occurred in the last 20 yearswith IT development, require shifts in the management paradigms or changing approach to business performance management. Traditional models focused on optimizing business performance by optimizing its subsystems do not yield fruitful results in dynamic environments. Logistics optimization of business dynamics in line with evolving business environment imposes itself as means to create adequate models for continuous business performance management. Dynamic optimization of business performance is the set of processes managed by implementing effective logistics management strategies, involving information, material and financial flows in incoming and outgoing communications with the environment, aimed at integrating and dynamizing all business subsystems in line with market demand. Business flexibility and adaptability are the fundamental control variables of the concept of logistics management and are the prerequisite for continuous business performance management in today's turbulent environment. Logistics management models seek to integrate success potentials, or the control variables - indicators of efficiency and effectiveness inbusiness performance, enabling managers to create simulation-based anticipatory management strategies aimed at dynamic optimization of business performance faced with discontinuous change in the business environment.
\end{abstract}

Keywords: Logistics Management, Logistics Flows, Flexibility, Adaptability

\section{Introduction}

Trends in enterprise development and enterprise environmental factors reveal changes in factors, and consequently the need to change approach to business performance management. Business flexibility and adaptability as the preconditions and the key variables of business performance management in contemporary global business environment that is characterised by dynamic changes, can be achieved most efficiently by implementing logistics concepts into business management systems. Logistics as a function of space-time transformations of information, material and financial resources seeks to establish and maintain links between subsystems and the environment. Focused on meeting customers' needs and requirements through processes, it is defined as the most convenient mean so gathering information needed for effective business management in modern business environment. Modern Enterprise Management implies identifying and developing logistics factors that affect dynamic business performance to achieve goals as indicators of business success, aimed at shaping an organization that continuously optimizes the process of achievement of company's goals.

A modern enterprise can be defined as a relatively open system. The enterprise receives its inputs from the environment and delivers business outcomes. To survive, an enterprise must constantly adapt to changes in the environment and influence the changes through its management decisions in line with its goals. Its impact on the environment implies information integration, or communication between the enterprise and its environment. Logistics is a function that manages processes of space-time transformations of goods from environmental inputs (suppliers), through qualitative transformation processes (production) to environmental outputs (customers). Logistics management systems are powered by information about customers' needs, availability of adequate inputs from suppliers and enterprise capabilities. Financial flows reflect information flows of a logistics system, which provide indicators for anticipatory management strategies for managing material flows as copy of the other two flows. Logistics flows manage value-added chains. A holistic logistics approach is focused on logistics flows and seeks to dynamically adjust business operations with changes in the environment to optimize business results. 
Continuous incoming and outgoing communications with the environment and interactions with other business functions through processes, enable continuous identification of opportunities and threats from the environment as well as strengths and weaknesses of the enterprise, which is the basis for creating enterprise strategies. Through a continuous process of gathering and processing information about the needs and requirements of the environment, logistics management operable, technologically and organisationally directs an enterprise to exploit opportunities and avoid threats, to successfully implement strategies that are aimed at achieving the enterprise's goals. The ability to react quickly to changes in the environment implies the ability and right to decide exactly what should be done to implement adequate strategies and achieve goals, and the ability to build an organization and its logistics management system to enable transforming creativity in management, in a system that is less technologically developed, into a systematic, rational process of transforming innovative ideas into products and services that optimally meet customers 'needs and requirements. Unlike other business subsystems of modern enterprises, logistics systems are essentially focused on dynamics and goals of an enterprise as a subsystem. A logistics system does not have its own specific goals, but its goals derive from the enterprise's goals. All other subsystems have their own partial goals that are often conflicting, sometimes with the goals of the enterprise as a system. Traditional parallel optimization models are not adequate for architecting individual business subsystems in continuous enterprise performance management faced with dynamic changes in all segments of the environment. A holistic logistics approach to enterprise performance management oriented to value-added logistics is the key source for creating management models that allow dynamic optimization of modern enterprise performance.

\section{Logistics Flows - Focus of Business Performance Models}

Successful management of a business throughout the logistics system, as a set of logistics processes and elements that are interrelated and function according to certain rules, aimed at achieving a particular goal, and represent a relatively isolated entity, relies on knowing a concept that determines the target function of business as an environment system. The aim of the logistics system is to reduce the lead time by effectively managing logistics value-added chains. In other words, logistics systems seek to optimally supply qualitative transformation processes through material, information and financial flows - in the right place, at the right time, at the right price, according to customers 'needs and business goals (Mason \& Lalwani, 2006). Managing logistics basic and management processes is concerned with achieving logistics goals which derive from the company's goals. The essence, therefore, of the logistics management concept isa holistic approach and dynamic-orientation - logistics value-added flows that lead to dynamic profit maximization.

\section{Scheme 1: Logistics Management Concept Model at Modern Enterprise}

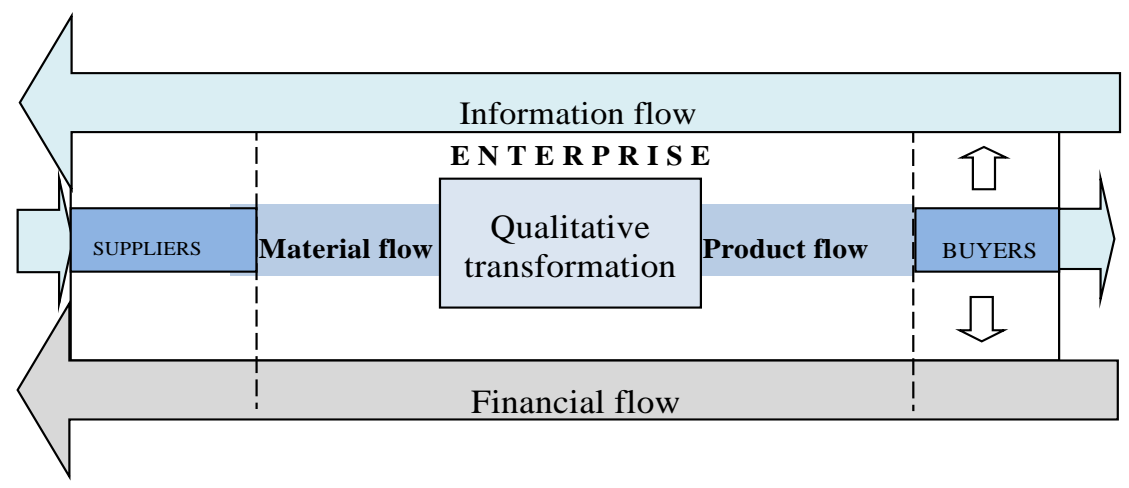

Source: AUTHOR

A logistics system as a specific intersystem or integrative system that goes beyond the boundaries of certain functions, business subsystems and the enterprise itself, focuses on the company's flows and goals as the system and can be defined as the most adequate means of dynamic optimization in business performance management. The logistics system connects and dynamizes all subsystems of an enterprise. Having this in mind and considering that business results of an enterprise as a business system should be more than the sum of the results of its subsystems, implementing the concept of logistics management allows focusing on relationships between such subsystems and managing their target synergistic dynamic behaviour, consistent with the company's goals. 
Throughout a networked logistics process organization and modern project logistics management methods, such as Critical Path Method (Lewis, J. P., 1995), logistics-oriented management strategies enable business performance optimization through continuous process improvement.

\section{Scheme 2: Networked Logistics Business Management Organization}

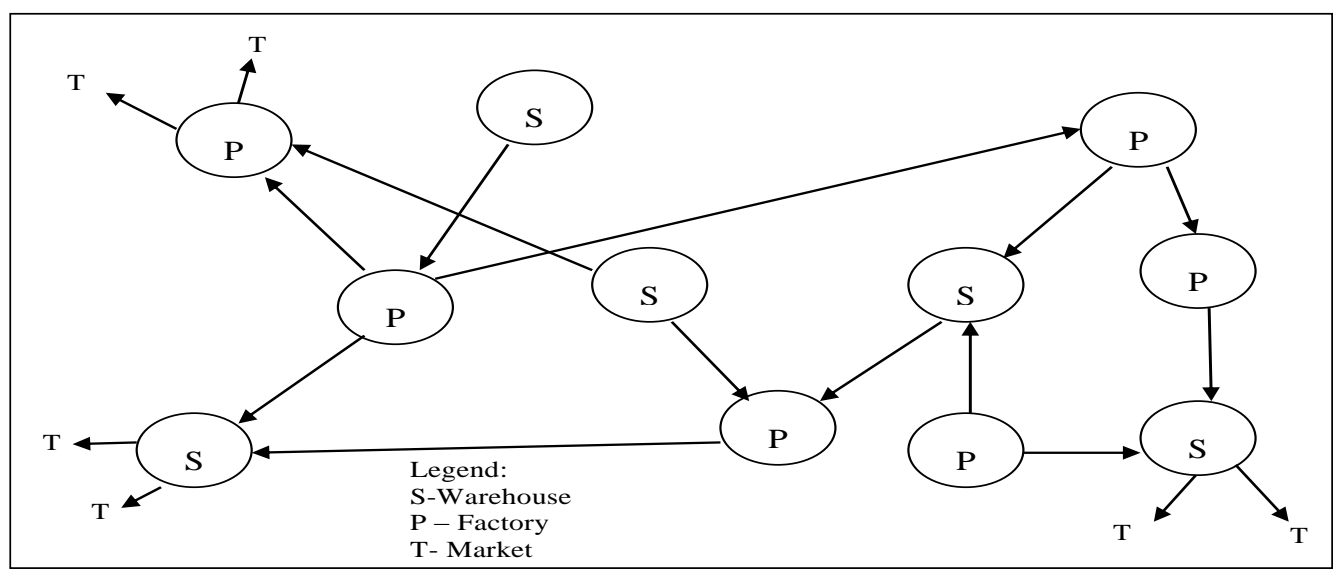

Source: AUTHOR

In a more dynamic, modern global business environment, the concept of logistics management becomes increasingly important for achieving competitive advantage and customer satisfaction (Kleab, 2017). To understand the concept more fully, it is necessary to focus directly on logistics value chain functions and assign the functions to variables of modern enterprise performance management model. Value chain (Porter, 2008) is defined as a systematic way of studying all the activities the company performs and the forms of their interaction for analysing the sources of competitive advantage or dynamic optimization of business performance. Logistics value chain models see businesses as customer value creation systems for the development of businesses to improve profits and increase employee income while satisfying the interests of other influential interest groups. Conceptualization of the process along the logistics value-added chain leads to building an infrastructure base for managing continuous business performance optimization of an enterprise defined as an environment subsystem, or supply chain from raw material to consumer (Hugos, 2011). Logistics information, material and financial flows tend to dynamically optimize qualitative transformation processes of adding value by maintaining continuous incoming and outgoing communications with the environment as a suprasystem.

\section{Scheme 3: Logistics Value-Added Chain Model}

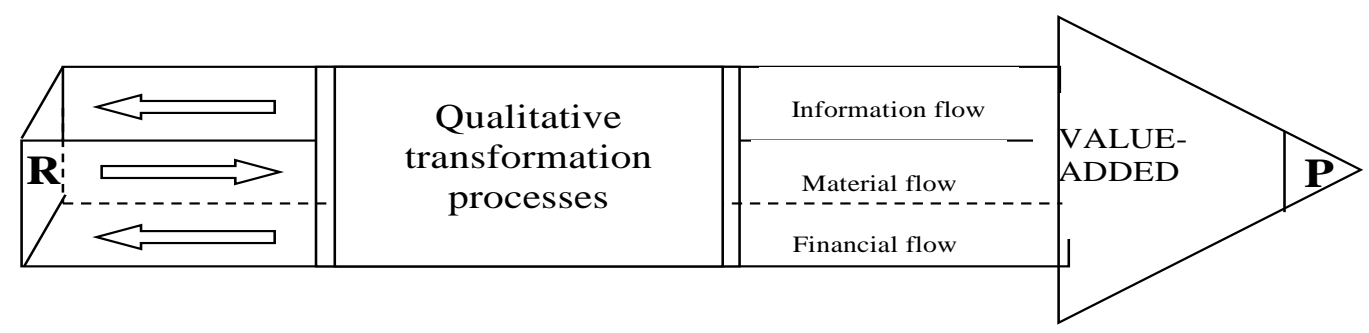

$\mathbf{R}-$ Expenses (Suppliers)

$\mathbf{P}$ - Revenues (Buyers)

\section{Source: AUTHOR}


Logistics material and information flows in logistics modern enterprise performance management models are optimized throughout financial flows or indicators. Financial flows run parallel to material and information flows. Flow optimization in a logistics system leads to dynamic optimization of modern enterprise performance.

\section{Logistics Model of Modern Enterprise Performance Management}

To run and manage a business effectively and efficiently throughout the logistics system, which, like all business systems, is complex, dynamic and stochastic, is possible by using adequate models. A model is a simplified image of reality. Managers need to use such simplifications of reality to reduce complex systems to basic structure or abstract systems/models, which enable them to understand and manage such system. A model is essentially any conceptual or practical system, a system that is analogous to the subject of research, used to explore the main subject or system. Since a logistics system, as well as enterprises and all human systems, is stochastic, its functions can be formulated only within probability limits and its control variables are inconvenient for developing a precise mathematical formulation. To manage a logistics system well with the aim to achieve goals is to use stochastic simulation models (Verma, 2014). A logistics system as a specific intersystem tends to dynamically integrate all business subsystems of an enterprise in incoming and outgoing communications with the environment. Managing a logistics system effectively to achieve dynamic optimisation of business performance requires using systematic, holistic models of business performance dynamics. A logistics system or business runs optimally if it has the ability to generate the result that is closest to the target function, or maximum profits in the long run. Logistics models of the value-added flows in modern enterprises see business success throughout the mutual influence that environment, resources and management have on each other.

\section{Scheme 4: Modern Enterprise Performance Model}

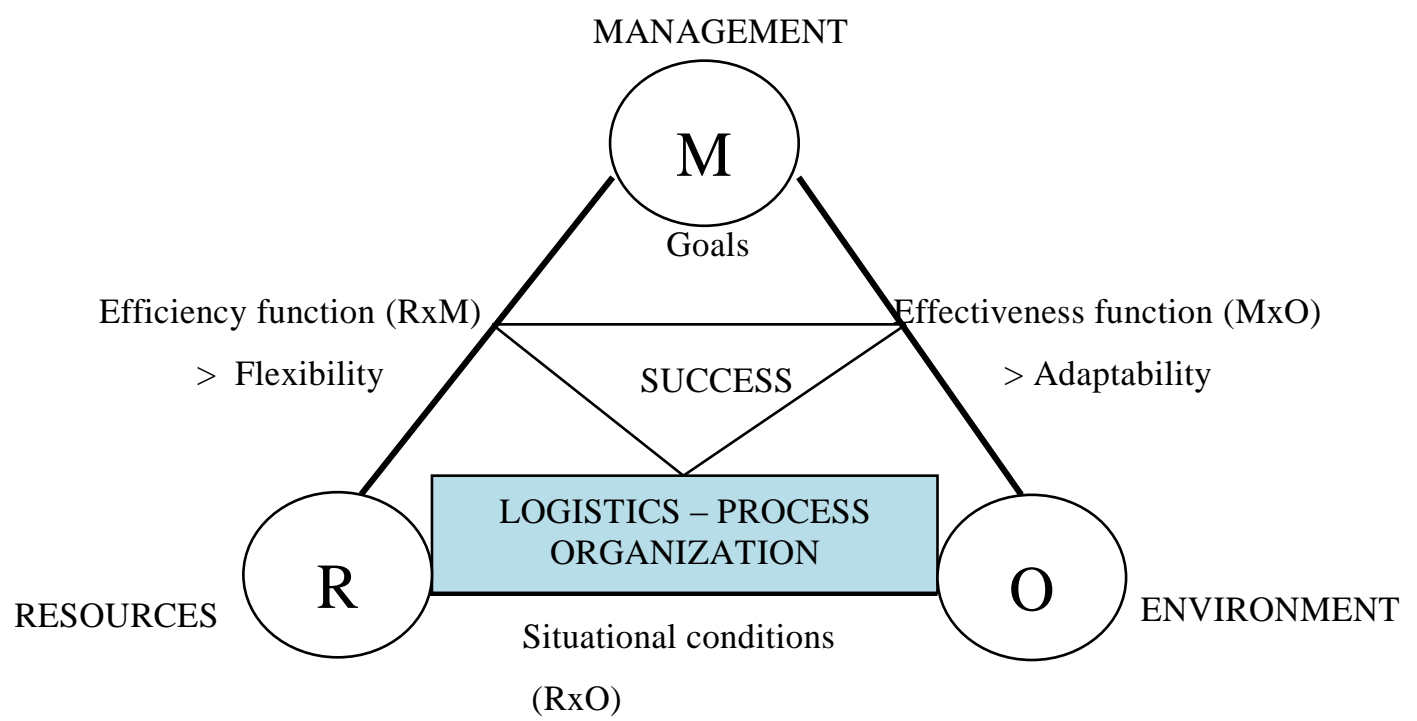

Source: AUTHOR

Situational conditions of an enterprise are the function of the enterprise environment and resources. In other words, an enterprise's situation is the resultant of interaction of the enterprise environment and its resources. Businesses are driven by resource, management and environment interdependence. Success criteria derive from the mutual influence between management and environment, or management and resources (Osmanagić-Bedenik, N., 1993). A logistics model of the value-added chain derives the efficiency function from interdependence of the enterprise resources and management. An enterprise, in accordance with the logistics model, runs efficiently when it achieves the most favourable relationship between goods and resources under the given conditions. Efficiency reflects the level of alignment within the enterprise, or the speed and harmony of the information, material and financial flows that result in the most favourable relationship between the effects and the roles. Efficiency is achieved through logistics operations management. 
It is, therefore, necessary to have day-to-day accurate information on the potential and actual relationships between the effects and the investments needed to produce these effects (Wurzner, S.K., et al., 1991). Efficiency is an indicator of flexibility of an enterprise to changes in the business environment.

According to the logistics model, effectiveness, which Korsiti and Cania (2016) consider crucial for survival of a business in a global environment reflects external harmony. It can be defined as a function of the relationship between management and environment. A business managed throughout the logistics system is effective when it fully meets customers' needs in line with its situation and knowledge. Effectiveness is built on key information on what are customers 'needs and how do you meet the needs of customers or buyers of products and services. Effectiveness is a logistics variable that can be considered about within strategic business management. Effectiveness reflects the degree of utilization of the potential for success and is an indicator of adaptability of businesses to changes in the business environment.

Flexibility and adaptability are the control variables of logistics thinking and logistics actions aimed at building logistics management models of dynamic business performance optimization. Intangible factors of success cannot be measured directly but are measured indirectly as changes in tangible factors caused by management actions. Flexibility and adaptability are indicators of enterprise development and growth. According to Tummali (2007), flexibility and adaptability are the most important indicators of logistics management, and indirectly business management. They provide information on how effective a business is adapting to changing business environment and what are its potentials for success. In other words, they indicate the level of dynamic business performance optimization.

Holistic logistics management models, which determine the logistical sequence of the control variables or interrelationships that reveal causal relationships between indicators, are intended to design successful enterprise management strategies aimed at building enterprise as a dynamic system in a contemporary turbulent environment. This reduces the problem of disparity between the new way of creating value and the traditional way of monitoring business.

\section{Logistics Management - Creator and Realizer of Dynamic Business Performance Optimization Strategies}

Computerized automation and robotics in manufacturing, as well as the equilibrium effects of technological progress, have exhausted all the possibilities of gaining competitive advantage by achieving higher efficiency in manufacturing processes. Customers are now more demanding, and their needs are more distinctive, resulting in dramatic shortening of life cycles of almost all products and services, which is a problem for many businesses (Zhao, et al., 2014). Efficient strategies for managing space-time processes of transformations of goods, energy, information and knowledge, geared towards customers' needs or demands, provide advantage over competitors in global dynamic markets.

Logistics managers, focused on designing systems of rapid transformations of new requirements and ideas into products and services that optimally meet customers' needs, become responsible for formulating strategies that focus on achieving company business goals. According to the cost-effectiveness principle, their task is to combine logistics potentials for success to effectively meet the ever-changing and growing customers' needs with minimum cost. Flexibility achieved through logistics management, fixed cost variability, rationalization of bonding capital and cost rationalization, through development of logistics' information and communication technologies, is a contribution of the logistics management concept to rationalization and revival of modern business. By seeking to substitute tangible logistics factors with information-based and human capital with information-based and management strategies, logistics managers tend to manage transformation processes by exploiting optimally the potentials of production to meet the ever-growing, increasingly diverse customers' needs. Combining logistics supply chain management strategies (customer and supplier integration through logistics processes) and cycle time compression is the right way to achieve full potential for success and competitive advantage. Supply chain management strategies seek to manage logistics flows across the enterprise in an organic and systematic manner, including strategic partnerships, with the aim of optimizing efficiency and effectiveness of logistics processes and business performance. Integrating customers into supply chains increases opportunities for customers to describe their needs and helps management to direct business through logistics processes. Cycle time compression strategies tend to shorten supply chain cycle time or the lead time. 
By systematically combining logistics strategies, businesses will be able to constantly adjust to changes in the market, and parallelly increase revenues and reduce costs through flexible logistics value-added processes aimed at dynamic business optimization (Zekić, Z., 2018).

The logistics concept of modern enterprise management represents a paradigm shift in management and implies innovative business management models. Complex decision-making problems in logistics management of modern enterprises impose the necessity to implement adequate holistic, dynamic models designed to help understand the problem and find the best solutions according to the objectives of the logistics system, or the enterprise. Decisionmaking models use algorithms to find the target function and at least two or more alternative solutions to come up with a solution that is optimal. Considering complexity of problems and inability to always achieve the true optimum, the optimal decision should be considered as the one that generates the result that is closest to the target function (Sikavica, P., et al., 1994).Talking about values associated to the optimum value theory, an optimum can be the extreme value, such as maximum profit, minimum cost or maximum profitability, depending on the target, which is characteristic of enterprises, or any economic system.

One of the biggest challenges facing logistics managers today is uncertainty. Events cannot be foreseen with certainty but within probability limits. So, logistics variables are model elements that are not suitable for precise quantitative estimates. Solving such problems requires the use of stochastic models that are used with simulation models to test the effects of decisions made before they are applied. Simulation is suitable for managing logistics processes where complexity of the problem makes it difficult, irrational or impossible to use deterministic models where optimization outcomes are precisely determined by using mathematical programming techniques (Zekić, Z., 2000).

Certain segments or elements of logistics systems can be optimized by using mathematical programming techniques. However, when speaking of dynamic optimization of a logistics system, which is not focused, like other enterprise systems, on individual segments but the entire business processor business dynamics, the most suitable are holistic simulation models. Simulation is an iterative process of action, reaction, and counteraction. The process is repeated for several iterations over a short period of time, where actions are initiative events, reactions are the responses from the environment. With simulation models, logistics managers can visualize how a logistics process is managed to the direction of dynamic business optimization. Focusing on future, intangible and hardly measurable metadata or previous contextual information is the basic postulate of logistics management, and a prerequisite for successful business management in discontinuous change in all business performance factors as the constant characteristic of today's world. Using management information systems to enable managers to make good un programmed decisions on unstructured issues through direct data and model interaction is a significant support in achieving continued business performance.

\section{Conclusion}

The concept of logistics management, which is focused on creating added value through logistics processes in enterprises as environment systems, is defined as an adequate approach to business performance management in today's dynamically changing environments. A holistic approach to business management dynamics in line with changes in the market, through efficiency in logistics processes, allows managers to manage dynamic optimisation of a company's business performance in accordance with its situational conditions. Focusing on flexibility and adaptability as the fundamental control variables of logistics optimization of business performance eleads to creating management models that integrate two success measures - efficiency and effectiveness, achieved through processes, serving as the leverage of dynamic business performance optimization. A holistic management model, where performance indicators are logically related to one another, that portray dynamics of value-added processes in enterprises in incoming and outgoing communications with the environment, enables managers to understand, simulate, anticipate and make better management decisions aimed at implementing continuous business performance management strategies in a constantly changing environment.

\section{References}

Mason, R., Lalwani, C. (2007.), Transport integration tools for supply chain management, International Journal of Logistics: Research and Applications, Vol. 9, No.1. 57-74.

Kleab, K. (2017.), Important of Supply Chain Management, International Journal of Scientific and Research Publications, Vol. 7, No. 9. 
Porter, E. M. (2008.),Konkurentskaprednost, Masmedia, Zagreb

Hugos, M. (2011.), Essentials of Supply Chain Management, Third Edition, Wiley and sons

Verma, A. K. (2014.), Enhancing Agility of Supply Chains using Stochastic, Discrete Event and Physical Simulation Models, 5 th International \& 26th All India Manufacturing Technology, Design and Research Conference (AIMTDR 2014) December 12th-14th, 2014, Guwahati, Assam, India

Osmanagić-Bedenik, N. (1993.), Potencijalipoduzeća: analizaidijagnozapotencijala u poslovanjupoduzeća, Zagreb, Alinea.

Korsita, B. iCania, L. (2016), Effective Management of Logistics - An Empirical Study of Albania, European Virtual Conference on Management Sciences and Economics

Zhao, X., et al. (2014.), The Evaluation and Selection of Supply Chain Models for Short-Life-Cycle Products, International Journal of Business and Management; Vol. 9, No. 5

Sikavica, P. et al.: (1994.). Poslovnoodlučivanje: teorijaipraksadonošenjaodluka, Zagreb, Informator

Tummala, R., Phillips, C.\& Johnson, M. (2007.), Assessing supply chain management success factors: a case study. Supply Chain Management:An International Journal, 11(2), 179-192.

Wurzner, S.K., et.al.(1991), EDV-Controlling in Kommunikationsnetzeintegrieren, Management Zeischrift, Industrielle Organisation4, p. 39., Zurich

Zekić, Z. (2000.), Logističkimenadžment, Glosa, Rijeka

Lewis, J.P. (1995.), Project Planning, Scheduling \& Control, McGraw-Hill, New York

Zekić, Z. (2018.), Supply Chain Management - a Contemporary Concept of Cooperative Competitiveness Development, OeconomicaJadertina, Vol. 8. No 1. 2018., Zadar 